$\xi=-1$

\title{
Transient investigation of stack-driven airflow process through rectangular cross-ventilated building with two vents in the absence of opposing flow in the upper opening
}

\author{
A. L. Muhammad ${ }^{1 *}$, M. Z. Ringim ${ }^{1}$, L. A. Isma'il ${ }^{2}$ \\ ${ }^{1}$ Department of Mathematics, Kano University of Science and Technology-Wudil, Nigeria \\ ${ }^{2}$ Department of Statistics, Kano University of Science and Technology-Wudil, Nigeria \\ *Corresponding author E-mail:mukhazah3@gmail.com
}

\begin{abstract}
Natural ventilation of building provides improvement of internal comfort and air quality conditions leading to a significant reduction of cool-ing energy consumption. Design of natural ventilation systems for many types of building is based on buoyancy forces. However, external wind flow can have significant effects on buoyancy- driven natural ventilation. The paper was concerned with transient investigation of airflow through two vents in the absence of opposing flow in the upper opening. A flow of this type represents a new class of boundary- layer flow problems in the building. Moreover, this is an exact solution of the complete Navier- Stokes Equations (including, buoyancy force term), which were then Non Dimensionalised using some dimensionless parameters and then solved analytically by separation of variable methods in which, the behavior of parameters in the results were predicts the velocity, temperature profiles together with volumetric airflow and mass transfer. The results were then evaluated numerically for several sets of values of the parameters in order to ascertain the best for optimal ventilation.
\end{abstract}

Keywords:Cross- Ventilated Building; Opposing Flow; Rectangular; Stack-Driven Airflow; Upper Opening.

\section{Introduction}

Generally, Air flow distributions in buildings are considered to be as a result of the knowledge of the exact air supply to a building. Knowledge of the exact air supply to a building is necessary to determine its thermal performance and the concentration of the indoor pollutants. The exchange of air can be achieved either by mechanical means (Mechanical ventilation) or through the large opening of the building envelope (Natural ventilation). Exchanges between external ambient and interior space of buildings caused by flows that are driven by wind or by temperature differences are the foundation of natural ventilation process. Of course,humans, who are increasingly spending more time indoors, to extend the possibilities of living in uncongenial or squally conditions etc, are pursuing natural ventilation. The improvements of the quality of the interior space in both its attractiveness, spaciousness, luminosity, and more importantly its proper natural ventilation are major concerns for designers of modern structures. Airflow modeling gives Architectures and Engineers the luxury to consider several design options in the minimum amount of time. As a result, the final design is not based on a tentative approach, but is a result of a professional design process considering several options and selecting the optimum solution. This can save on capital and running costs save time on commissioning. Many attempts to investigate this phenomenon have been made by some researchers. [2] Studied a convective heat and mass-transfer through large openings, which plays an important role in the thermal behavior in buildings. [1] Investigated airflow process in single-sided natural ventilation by using a computational fluid dynamics (CFD) method together with analytical and empirical models. [4] Considered building having two openings at different vertical level on opposite walls, the heights of the two openings are relatively small, and the areas of the top and bottom openings are $A_{t}$ and $A_{b}$ respectively. The study also considered an indoor source of heat $E$, and the wind force can assist or oppose the thermal buoyancy force, when the indoor temperature is uniform. [3] Presented an experimental and numerical analyses of heat transfer and air flow on an interactive building façade. [5] Investigated air flow rate across a vertical opening induced by a thermal source in a room, various parameters were used in designing natural ventilation. [6] Considered wind-driven cross ventilation in building with small openings. [8] Studied airflow process across vertical vents induced by stackdriven effect with an opposing flow in one of the openings was presented. [9] also recently presented an investigation of stackdriven airflow through rectangular cross- ventilated building with two openings using analytic technique. [7] Presented a simple mathematical model of stack ventilation flows in multicompartment buildings, with a view to providing an intuitive understanding of the physical processes governing the movement of air and heat through naturally ventilated buildings.

The main objective of this paper is to analytically determine the behavior of parameters involve in the results that predicts the temperature, velocity profiles together with volumetric airflow and mass transfer in a rectangular un- stratified cross- ventilated building with two openings on a vertical wall and discussed the asymptotic behavior of the results graphically. This is the novel approach which will lead to better understanding of the phenomenon and help in optimizing the designs for better natural ventilation. The organization of the paper is as follows. Section 2 contains the description of the building and statement of problem under study. Section 3 present Material and method while section 4 present 
formulations of the models. The results of our numerical simulations are presented in section 5. Finally, we make a concluding remark in Section 6.

\section{Description/ statement of problem}

In this paper, transient investigation of airflow process through rectangular cross- ventilated building with two vents in the absence of opposing flow in each of the upper opening is considered. A flow of this type represents a new class of boundary- layer flow problems in the building envelope. Moreover, this is an exact solution of the complete Navier- Stokes Equations (including, buoyancy force term). The building considered is un-stratified crossventilated rectangular building with two openings. In which the building has one upper and one lower rectangular opening. The upper opening has an area of $0.7 \mathrm{~m} \times 1.0 \mathrm{~m}$, while the lower opening is $0.7 \mathrm{~m} \times 2.0 \mathrm{~m}$. Dimension of the building is $5.3 \mathrm{~m} \times 3.6 \mathrm{~m} \times$ $2.8 \mathrm{~m}$ with air as the connecting fluid. The domain envelops were separated from one another by a vertical rectangular openings of heighty $^{*}$ and widthx ${ }_{\mathrm{w}}$, which is illustrated in Figure 1. The density of air in the building is maintained at $\rho_{0}$ with temperature at $\dot{\theta}^{*}$ and pressure $\mathrm{P}$.

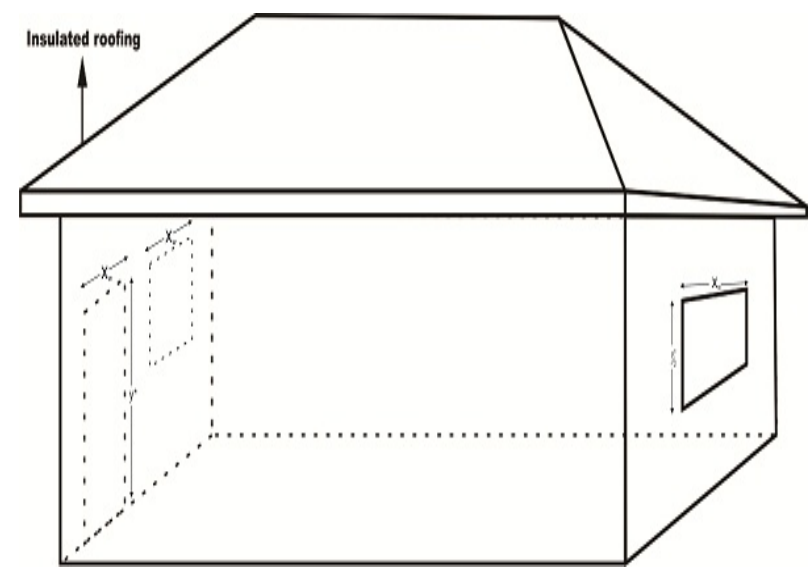

Fig. 1:Diagram of Un-Stratified Cross-Ventilated Rectangular Building with Two Openings.

\section{Material and method}

In this paper we discussed the temperature- velocity- profiles together with volumetric and mass transfer for transient Stack- driven airflow through rectangular openings in building with two openings in the presence of uniform interior temperature (see Figure 1). Schematic diagrams of airflow process inside the building and the one vertical upper vent are shown in Figure 2 and 3 below. The flow is transient that depends on the height of the opening on the vertical walls. Airflow is assumed to be at low speed so that it will behave like incompressible fluid. Internal heat source is negligible $\mathrm{q} \ll 1$ (see Figure 2 and 3 ). An approximation of reduced gravity is invoked. One Dimensional Navier Stokes Equations with appropriate boundary conditions will describe the problem. The model Equations are written in a dimensionless form and solved analytically by means of separation of variable methods Graphical study of the results has been made using MATLAB Computer package.

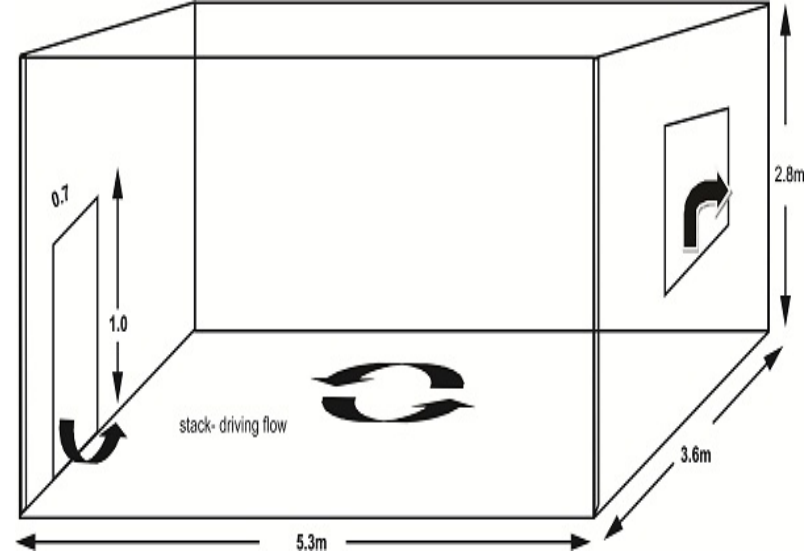

Fig. 2:Schematic Diagram of Airflow Process Inside Un- Stratified CrossVentilated Rectangular Building with Two Openings.

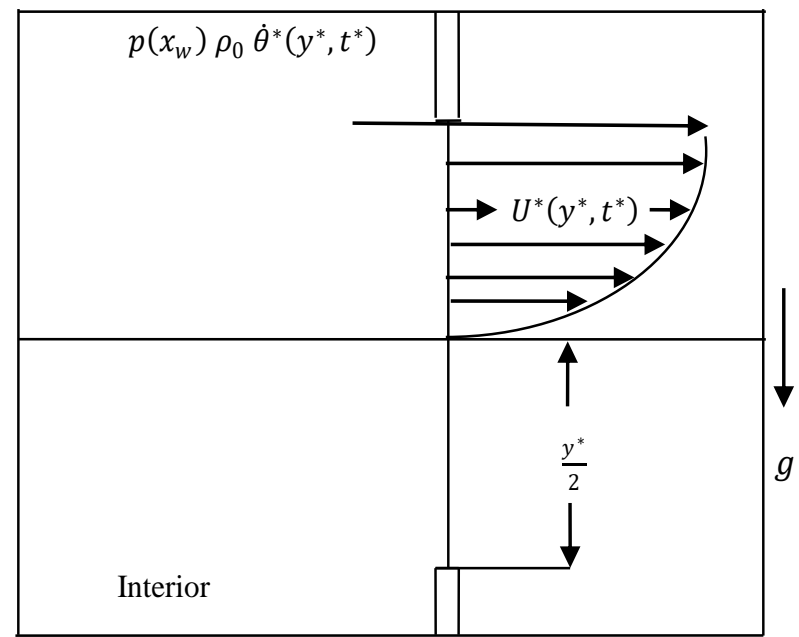

Fig. 3:Schematic Diagram of Airflow Process across One of the Vertical Vent in Rectangular Building with Two Openings.

Notations and Greek's words

$\mathrm{C}_{1}, \mathrm{C}_{2}, \mathrm{C}_{3}, \mathrm{C}_{4} \quad$ Coefficients

$\mathrm{P}_{1}$

$\mathrm{A}^{*}$

$\mathrm{x}_{\mathrm{W}}$

$\mathrm{y}$

$y^{*}$

$c_{d}$

G

$P$

$t^{*}$

$\mathrm{T}$

$t_{\max }$

$\mathrm{U}$

$\mathrm{U}^{*}\left(\mathrm{y}^{*}, \mathrm{t}^{*}\right)$

$\mathrm{U}_{\mathrm{S}}^{*}\left(\mathrm{y}^{*}\right)$

$\mathrm{U}_{\mathrm{u}}^{*}\left(\mathrm{y}^{*}, \mathrm{t}^{*}\right)$

$\mathrm{m}^{*}\left(\mathrm{y}^{*}, \mathrm{t}^{*}\right)$

$\mathrm{Q}^{*}\left(\mathrm{y}^{*}, \mathrm{t}^{*}\right)$

$\mathrm{U}_{\mathrm{p}}\left(\mathrm{y}^{*}\right), \mathrm{U}_{\mathrm{p}}\left(\mathrm{y}^{*}, \mathrm{t}^{*}\right)$ Particular solutions

$\frac{\mathrm{y}^{*}}{2}$

$\mathrm{L}$

$\alpha$

$v$

$\beta$

$\theta_{0}$

$\Delta \dot{\theta}$

$\dot{\theta}_{\mathrm{s}}^{*}\left(\mathrm{y}^{*}\right)$

$\dot{\theta}_{\mathrm{u}}^{*}\left(\mathrm{y}^{*}, \mathrm{t}^{*}\right)$

Air pressure

Maximum time

Neutral height

Dummy variable

Thermal diffusivity

Kinematic viscosity
Separation constants

Total area of the openings

Width of the openings

Dimensional height of the openings

Dimensionless height of the openings

Discharge coefficient

Acceleration due to gravity

Dimensionless time intervals

Dimensional time intervals

Dimensional velocity profile

Dimensionless velocity profiles

Dimensionless steady velocity profiles

Dimensionless unsteady velocity profiles

Dimensionless mass - transfer

Dimensionless volumetric airflow

Length scale of the height of the opening

Thermal expansion coefficient

Effective thermal coefficient

Dimensional change of air temperature

Dimensionless steady temperature profiles

Dimensionless unsteady temperature profiles 
$\dot{\theta} \quad$ Dimensional temperature of air

$\dot{\theta}^{*}\left(\mathrm{y}^{*}, \mathrm{t}^{*}\right)$ Dimensionless temperature profiles

$\rho_{0} \quad$ Constant density of the air

Dimensionless parameter

Pr Prandtl number

Subscripts

w Width

\section{Model formulation}

The convective motion induced by stack- driven effect as illustrated in Figure 2 and 3 is described by one dimensional NavierStokes Equation given as,

$\frac{\partial \mathrm{U}}{\partial \mathrm{t}}=\mathrm{g} \beta \Delta \dot{\theta}+v \frac{\partial^{2} \mathrm{U}}{\partial \mathrm{y}^{2}}$

$\frac{\partial \dot{\theta}}{\partial \mathrm{t}}=\alpha \frac{\partial^{2} \dot{\theta}}{\partial \mathrm{y}^{2}}$

With the following dimensional boundary conditions as,

$$
\begin{gathered}
0 \leq \mathrm{y} \leq 2, \mathrm{t} \geq 0, \mathrm{U}(0)=0, \mathrm{U}(2)=0, \mathrm{U}(0, \mathrm{t})=0, \mathrm{U}(2, \mathrm{t}) \\
=0, \theta(0)=-\theta_{0}, \theta(2)=1-\theta_{0}, \theta(0, \mathrm{t}) \\
=0, \theta(2, \mathrm{t})=0 .
\end{gathered}
$$

By scalingy withy* $\mathrm{L}$, velocity $\mathrm{U}$ with $\frac{\mathrm{U}^{*} \mathrm{~g} \beta \Delta \theta \mathrm{L}^{2}}{\alpha}, \mathrm{t}=\frac{\mathrm{t}^{*} \mathrm{~L}^{2}}{\alpha}$, and introducing $\dot{\theta}$ with $\dot{\theta}^{*} \Delta \theta+\theta_{0}$, where $\Delta \dot{\theta}=\dot{\theta}-\theta_{0}$.

In dimensionless form the above Equations (1) and (2) may be expressed as,

$\frac{\partial \mathrm{U}^{*}}{\partial \mathrm{t}^{*}}=\operatorname{Pr} \frac{\partial^{2} \mathrm{U}^{*}}{\partial \mathrm{y}^{*}}+\dot{\theta}^{*}\left(\mathrm{y}^{*}, \mathrm{t}\right)$

$\frac{\partial \dot{\theta}^{*}}{\partial \mathrm{t}^{*}}=\frac{\partial^{2} \dot{\theta}^{*}}{\partial \mathrm{y}^{*}}$

With the following dimensionless boundary conditions as,

$$
\begin{aligned}
0 \leq \mathrm{y}^{*} \leq 1, \mathrm{t}^{*} \geq 0, & \mathrm{U}^{*}(0)=0, \mathrm{U}^{*}(1)=0, \mathrm{U}_{\mathrm{u}}^{*}\left(0, \mathrm{t}^{*}\right) \\
& =0, \mathrm{U}_{\mathrm{u}}^{*}\left(1, \mathrm{t}^{*}\right)=0, \frac{\partial \mathrm{U}^{*}\left(1, \mathrm{t}_{\max }\right)}{\partial \mathrm{y}^{*}}=\mathrm{U}_{0}, \dot{\theta}^{*}(0) \\
& =-\theta_{0}, \dot{\theta}^{*}(1)=1-\theta_{0}, \dot{\theta}_{\mathrm{u}}^{*}\left(0, \mathrm{t}^{*}\right) \\
& =0, \dot{\theta}_{\mathrm{u}}^{*}\left(1, \mathrm{t}^{*}\right)=0, \dot{\theta}_{\mathrm{u}}^{*}\left(1, \mathrm{t}_{\max }\right)=\text { Sint }^{*} .
\end{aligned}
$$

The steady state Equation in (4) using the boundary condition for dimensionless temperature profiles is,

$\frac{\mathrm{d}^{2} \dot{\theta}^{*}}{\mathrm{dy}^{* 2}}=0$

$0 \leq \mathrm{y}^{*} \leq 1, \dot{\theta}^{*}(0)=-\theta_{0}, \dot{\theta}^{*}(1)=1-\theta_{0}$

yield the resulting solution as,

$\dot{\theta}_{\mathrm{s}}^{*}\left(\mathrm{y}^{*}\right)=\mathrm{y}^{*}-\theta_{0}$

The Equation for the time dependent is one given in Equation (4) as,

$\frac{\partial \dot{\theta}^{*}}{\partial \mathrm{t}^{*}}=\frac{\partial^{2} \dot{\theta}^{*}}{\partial \mathrm{y}^{*}}$

The separation between the steady and unsteady part of solution are as follows,

$\dot{\theta}^{*}\left(\mathrm{y}^{*}, \mathrm{t}\right)=\dot{\theta}_{\mathrm{s}}^{*}\left(\mathrm{y}^{*}\right)+\dot{\theta}_{\mathrm{u}}^{*}\left(\mathrm{y}^{*}, \mathrm{t}^{*}\right)$

The Equation (4) is also valid for the unsteady part of the solution as, $\frac{\partial \dot{\theta}_{\mathrm{u}}^{*}}{\partial \mathrm{t}^{*}}=\frac{\partial^{2} \dot{\theta}_{\mathrm{u}}^{*}}{\partial \mathrm{y}^{* 2}}$

With the following boundary condition for dimensionless temperature profiles as,

$$
0 \leq \mathrm{y}^{*} \leq 1, \dot{\theta}_{\mathrm{u}}^{*}\left(0, \mathrm{t}^{*}\right)=0, \dot{\theta}_{\mathrm{u}}^{*}\left(1, \mathrm{t}^{*}\right)=0, \dot{\theta}_{\mathrm{u}}^{*}\left(1, \mathrm{t}_{\max }\right)=\text { Sint }^{*}
$$

The separation given by,

$\dot{\theta}_{u}^{*}\left(y^{*}, t^{*}\right)=Y\left(y^{*}\right) T\left(t^{*}\right)$

Leads with Equation (8) to the eigen value problem as,

$\frac{T^{\prime}}{T}=\frac{Y^{\prime \prime}}{Y}+\frac{C Y^{\prime}}{Y}=-P_{1}^{2}$ for $P_{1}>0$

With generalized solution of the form,

$\dot{\theta}_{u}^{*}\left(y^{*}, t^{*}\right)=K_{3} e^{-P_{1}^{2} t^{*}} \sinh P_{1} y^{*}$

Equation (11), together with the homogeneous dimensionless boundary conditions yields to,

$\dot{\theta}_{u}^{*}\left(y^{*}, t^{*}\right)=K_{3} e^{-n^{2} \pi^{2} t^{*}} \sinh n \pi y^{*}$

Similarly, using $\dot{\theta}_{u}^{*}\left(1, t_{\max }\right)=\sin t^{*}$, from Equation (12) one obtains,

$K_{3}=\frac{\sin t^{*} e^{-n^{2} \pi^{2} t_{\max }}}{\sin n \pi}$ for, $t^{*} \geq 0, n=\frac{1}{2}, \frac{3}{2}, \frac{5}{2}, \ldots$

The resulting Equation (12) becomes,

$\dot{\theta}_{u}^{*}\left(y^{*}, t^{*}\right)=\frac{\sin t^{*} e^{-n^{2} \pi^{2}\left(t_{\max }-t^{*}\right)}}{\sin n \pi} \sinh \pi \pi y^{*}$.

The general time dependent solution for dimensionless temperature profiles is,

$\dot{\theta}^{*}\left(y^{*}, t^{*}\right)=y^{*}-\theta_{0}+\frac{\sin t^{*} e^{-n^{2} \pi^{2}\left(t_{\max }-t^{*}\right)}}{\operatorname{sinn} \pi} \sinh n \pi y^{*}$.

The steady state Equation and boundary condition for dimensionless velocity profiles is,

$\operatorname{Pr} \frac{d^{2} U^{*}}{d y^{* 2}}=-\dot{\theta}^{*}\left(y^{*}\right)$

$0 \leq y^{*} \leq 1, U^{*}(0)=0, U^{*}(1)=0$.

Plugging the Equation (6) in Equation (15) yields to,

$\operatorname{Pr} \frac{d^{2} U^{*}}{d y^{* 2}}=-\left(y^{*}-\theta_{0}\right)$

Starting with the homogeneous part of Equation (16), one obtained the complementary solution as,

$U_{c}\left(y^{*}\right)=C_{1}+C_{2} y^{*}$

By employing the variation of parameter methods, one can write the particular solution as,

$U_{P}\left(y^{*}\right)=\frac{1}{\operatorname{Pr}}\left(\frac{\theta_{0} y^{* 2}}{2}-\frac{y^{* 3}}{6}\right)$

The general solution is given by,

$U_{s}^{*}\left(y^{*}\right)=C_{1}+C_{2} y^{*}+\frac{1}{\operatorname{Pr}}\left(\frac{\theta_{0} y^{* 2}}{2}-\frac{y^{* 3}}{6}\right)$ 
The two constant which appear in Equation (19) can be determined by prescribing the boundary condition for the velocity field in Equation (5), thus obtaining,

$U_{S}^{*}\left(y^{*}\right)=\frac{1}{P r}\left(\frac{\theta_{0} y^{* 2}}{2}-\frac{y^{* 3}}{6}-\left(\frac{3 \theta_{0}-1}{6}\right) y^{*}\right)$.

Where $C_{1}=0, C_{2}=-\frac{1}{P r}\left(\frac{\theta_{0}}{2}-\frac{1}{6}\right)$ are the two arbitrary constant. Plugging the Equation (14) in (3) yields to,

$\frac{\partial U^{*}}{\partial t^{*}}=\operatorname{Pr} \frac{\partial^{2} U^{*}}{\partial y^{* 2}}+y^{*}-\theta_{0}+\frac{\sin t^{*} e^{-n^{2} \pi^{2}\left(t_{\max }-t^{*}\right)}}{\sin n \pi} \sinh n \pi y^{*}$.

The separation between the steady and unsteady part of solution are as follows,

$U^{*}\left(y^{*}, t^{*}\right)=U_{s}^{*}\left(y^{*}\right)+U_{u}^{*}\left(y^{*}, t^{*}\right)$.

The Equation (21) is also valid for the unsteady part of the solution as,

$$
\frac{\partial U_{u}^{*}}{\partial t^{*}}=\operatorname{Pr} \frac{\partial^{2} U_{u}^{*}}{\partial y^{* 2}}+y^{*}-\theta_{0}+\frac{\sin t^{*} e^{-n^{2} \pi^{2}\left(t_{\max }-t^{*}\right)}}{\operatorname{sinn} \pi} \sinh n \pi y^{*} .
$$

With the following boundary condition for velocity profiles as,

$0 \leq y^{*} \leq 1, U_{u}^{*}\left(0, t^{*}\right)=0, U_{u}^{*}\left(1, t^{*}\right)=0$.

Starting with the homogeneous part of Equation (23), one obtain

$\frac{d U^{*}}{d t^{*}}-\operatorname{Pr} \frac{d^{2} U^{*}}{d y^{* 2}}=0$

The separation is given by the complementary solution as,

$U_{c}^{*}\left(y^{*}, t^{*}\right)=Y\left(y^{*}\right) T\left(t^{*}\right)$

Leads with Equation (24) to the eigen value problem as,

$\frac{T^{\prime}}{\operatorname{PrT}}=\frac{Y^{\prime \prime}}{Y}=-P_{1}^{2}$ for $P_{1}>0$.

The generalized complementary solution is of the form,

$U_{C}^{*}\left(y^{*}, t^{*}\right)=e^{-P_{1}^{2} t^{*}}\left(C_{3} \cos P_{1} y^{*}+C_{4} \sin P_{1} y^{*}\right)$

The particular solution for Equation (21) is given by,

$U_{P}^{*}\left(y^{*}, t^{*}\right)=y^{*} t^{*}-\frac{\operatorname{Pr} y^{* 3}}{6}-\left(\theta_{0} t^{*}-\frac{\theta_{0} P r y^{* 2}}{2}\right)+$
$\frac{\sin t^{*} e^{-n^{2} \pi^{2}\left(t_{\max }-t^{*}\right)}}{\sin n \pi} \sin n \pi y^{*}\left(t^{*}-n^{2} \pi^{2}(1-\operatorname{Pr})\right)$

The generalized solution of unsteady velocity profiles is of the form,

$U_{u}^{*}\left(y^{*}, t^{*}\right)=U_{C}^{*}\left(y^{*}, t^{*}\right)+U_{P}^{*}\left(y^{*}, t^{*}\right)$.

This yield to,
$U_{u}^{*}\left(y^{*}, t^{*}\right)=e^{-P_{1}^{2} t^{*}}\left(C_{3} \cos P_{1} y^{*}+C_{4} \sin P_{1} y^{*}\right)+y^{*} t^{*}-\frac{\text { Pry }{ }^{* 3}}{6}-$ $\left(\theta_{0} t^{*}-\frac{\theta_{0} P r y^{* 2}}{2}\right)+\frac{\sin t^{*} e^{-n^{2} \pi^{2}\left(t_{\max }-t^{*}\right)}}{\operatorname{sinn} \pi} \operatorname{sinn} \pi y^{*}\left(t^{*}\right.$

$\left.n^{2} \pi^{2}(1-P r)\right)$

The two constant which appear in Equation (29) can be determined by prescribing the boundary condition for the velocity field in Equation (22), thus obtaining,

$U^{*}\left(y^{*}, t^{*}\right)=\frac{1}{\operatorname{Pr}}\left(\frac{\theta_{0} y^{* 2}}{2}-\frac{y^{* 3}}{6}-\left(\frac{3 \theta_{0}-1}{6}\right) y^{*}\right)+$

$e^{-P_{1}^{2} t^{*}}\left(C_{3} \cos P_{1} y^{*}+C_{4} \sin P_{1} y^{*}\right)+y^{*} t^{*}-\frac{\operatorname{Pr} y^{* 3}}{6}-\left(\theta_{0} t^{*}-\right.$ $\left.\frac{\theta_{0} P r y^{* 2}}{2}\right)+\frac{\sin t^{*} e^{-n^{2} \pi^{2}\left(t_{\max }-t^{*}\right)}}{\sin n \pi} \operatorname{sinn} \pi y^{*}\left(t^{*}-n^{2} \pi^{2}(1-\operatorname{Pr})\right)$. (30)

Where, $C_{3}=\theta_{0} t^{*} e^{P_{1}^{2} t^{*}}, C_{4}=\frac{e^{P_{1}^{2} t^{*}}}{\sin P_{1}}\left(-\theta_{0} t^{*} \cosh P_{1}-t^{*}+\frac{P r}{6}-\right.$ $\left.\left(\frac{P r}{2}-t^{*}\right) \theta_{0}-\sin ^{*} e^{-n^{2} \pi^{2}\left(t_{\max }-t^{*}\right)}\left(t^{*}-n^{2} \pi^{2}(1-\operatorname{Pr})\right)\right)$.

Therefore, the general time dependent solution for dimensionless velocity profiles is given by,

$$
\begin{aligned}
U^{*}\left(y^{*}, t^{*}\right)=\frac{1}{\operatorname{Pr}}\left(\frac{\theta_{0} y^{* 2}}{2}-\frac{y^{* 3}}{6}-\left(\frac{3 \theta_{0}-1}{6}\right) y^{*}\right)+\theta_{0} t^{*} \cos P_{1} y^{*} \\
+\frac{\sinh P_{1} y^{*}}{\sin P_{1}}\left(-\theta_{0} t^{*} \cos P_{1}-t^{*}+\frac{\operatorname{Pr}}{6}\right. \\
\quad-\left(\frac{\operatorname{Pr}}{2}-t^{*}\right) \theta_{0} \\
\left.-\operatorname{sint}^{*} e^{-n^{2} \pi^{2}\left(t_{\max }-t^{*}\right)}\left(t^{*}-n^{2} \pi^{2}(1-\operatorname{Pr})\right)\right) \\
+y^{*} t^{*}-\frac{\operatorname{Pr} y^{* 3}}{6}-\theta_{0} t^{*}+\frac{\theta_{0} \operatorname{Pr} y^{* 2}}{2} \\
+\frac{\sin t^{*} e^{-n^{2} \pi^{2}\left(t_{\max }-t^{*}\right)}}{\sin \pi} \operatorname{sinn} \pi y^{*}\left(t^{*}-n^{2} \pi^{2}(1-\operatorname{Pr})\right)(32)
\end{aligned}
$$

The volumetric airflow is defined in Equation (33) below,

$Q^{*}\left(y^{*}, t^{*}\right)=A^{*} c_{d} \int_{s=0}^{s=\frac{y^{*}}{2}} U^{*}(s) d s d t^{*}$

Putting Equation (32) in (33), one obtains

$Q^{*}\left(y^{*}, t^{*}\right)=A^{*} c_{d} \int_{S=0}^{s=\frac{y^{*}}{2}}\left[\frac{1}{\operatorname{Pr}}\left(\frac{\theta_{0} y^{* 2}}{2}-\frac{y^{* 3}}{6}-\left(\frac{3 \theta_{0}-1}{6}\right) y^{*}\right)+\right.$ $\theta_{0} t^{*} \cos P_{1} y^{*}+\frac{\sinh P_{1} y^{*}}{\sin P_{1}}\left(-\theta_{0} t^{*} \cos P_{1}-t^{*}+\frac{P r}{6}-\left(\frac{P r}{2}-t^{*}\right) \theta_{0}-\right.$ $\left.\sin t^{*} e^{-n^{2} \pi^{2}\left(t_{\max }-t^{*}\right)}\left(t^{*}-n^{2} \pi^{2}(1-\operatorname{Pr})\right)\right)+y^{*} t^{*}-\frac{\operatorname{Pr} y^{* 3}}{6}-$ $\theta_{0} t^{*}+\frac{\theta_{0} P r y^{* 2}}{2}+\frac{\operatorname{sint}^{*} e^{-n^{2} \pi^{2}\left(t_{\max }-t^{*}\right)}}{\sin n \pi} \sin n \pi y^{*}\left(t^{*}-n^{2} \pi^{2}(1-\right.$ Pr)). $] d s d t^{*}$

Where, $s$ is a dummy variable.

The results for Equation (34) yields to volumetric airflow as, 


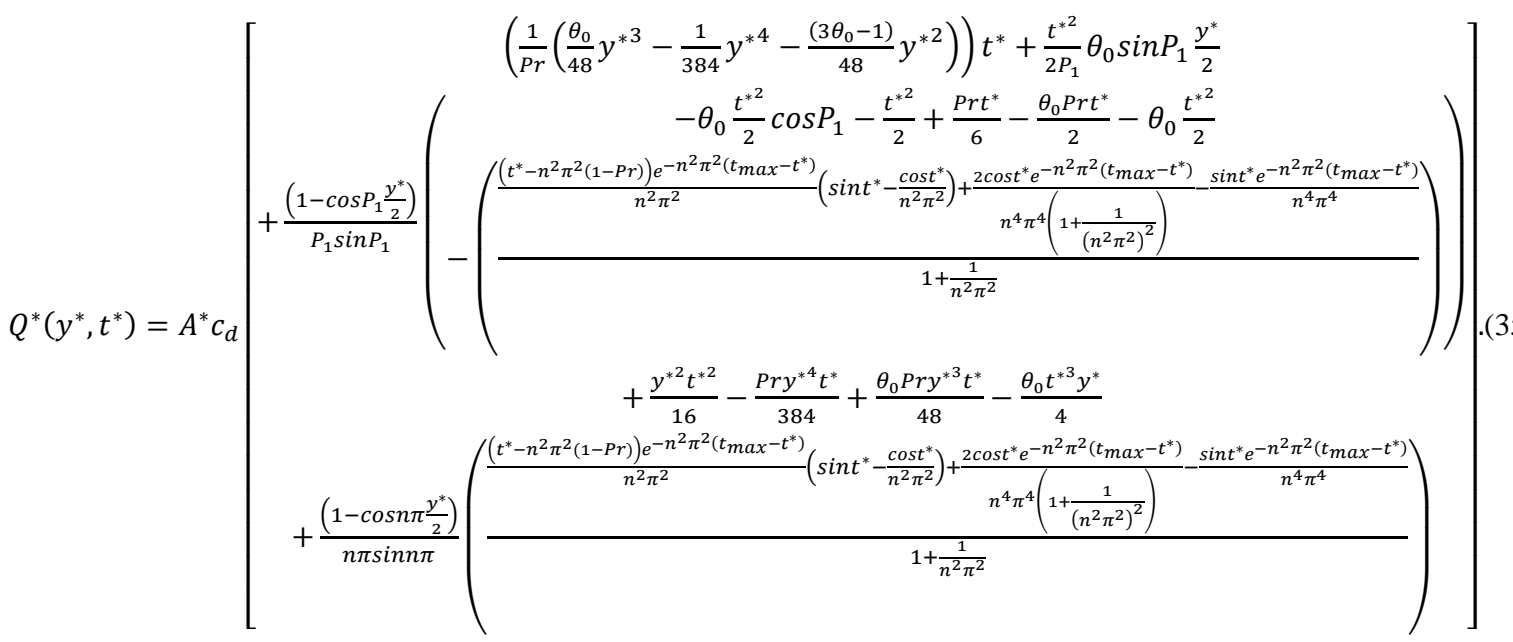

The mass transfer is given by Equation (36) below as,

$$
m^{*}\left(y^{*}, t^{*}\right)=\rho_{0} Q^{*}\left(y^{*}\right)
$$

By plugging Equation (35) in (36), one obtains the mass transfer as,

$$
\begin{aligned}
& m^{*}\left(y^{*}, t^{*}\right)=A^{*} c_{d} \rho_{0}\left[\left(\frac{1}{\operatorname{Pr}}\left(\frac{\theta_{0}}{48} y^{* 3}-\frac{1}{384} y^{* 4}-\frac{\left(3 \theta_{0}-1\right)}{48} y^{* 2}\right)\right) t^{*}+\frac{t^{* 2}}{2 P_{1}} \theta_{0} \sin P_{1} \frac{y^{*}}{2}+\frac{\left(1-\cos P_{1} \frac{y^{*}}{2}\right)}{P_{1} \sin P_{1}}\left(-\theta_{0} \frac{t^{* 2}}{2} \cos P_{1}-\frac{t^{* 2}}{2}+\frac{\operatorname{Pr} t^{*}}{6}-\frac{\theta_{0} P r t^{*}}{2}-\right.\right. \\
& \theta_{0} \frac{t^{* 2}}{2}-\left(\frac{\left.\frac{\left(t^{*}-n^{2} \pi^{2}(1-P r)\right) e^{-n^{2} \pi^{2}\left(t_{\max }-t^{*}\right)}}{n^{2} \pi^{2}}\left(\sin t^{*}-\frac{\cos t^{*}}{n^{2} \pi^{2}}\right)+\frac{2 \cos t^{*} e^{-n^{2} \pi^{2}\left(t_{\max }-t^{*}\right)}}{n^{4} \pi^{4}\left(1+\frac{1}{\left(n^{2} \pi^{2}\right)^{2}}\right)}-\frac{\sin t^{*} e^{-n^{2} \pi^{2}\left(t_{\max }-t^{*}\right)}}{n^{4} \pi^{4}}\right)}{1+\frac{1}{n^{2} \pi^{2}}}\right)+\frac{y^{* 2} t^{* 2}}{16}-\frac{\operatorname{Pr} y^{* 4} t^{*}}{384}+\frac{\theta_{0} \operatorname{Pr} y^{* 3} t^{*}}{48}-\frac{\theta_{0} t^{* 3} y^{*}}{4}+ \\
& \left.\frac{\left(1-\cos n \pi \frac{y^{*}}{2}\right)}{n \pi \sin n \pi}\left(\frac{\left.\frac{\left(t^{*}-n^{2} \pi^{2}(1-P r)\right) e^{-n^{2} \pi^{2}\left(t_{\max }-t^{*}\right)}}{n^{2} \pi^{2}}\left(\sin t^{*}-\frac{\cos t^{*}}{n^{2} \pi^{2}}\right)+\frac{2 \cos t^{*} e^{-n^{2} \pi^{2}\left(t_{\max }-t^{*}\right)}}{n^{4} \pi^{4}\left(1+\frac{1}{\left(n^{2} \pi^{2}\right)^{2}}\right)}-\frac{\sin t^{*} e^{-n^{2} \pi^{2}\left(t_{\max }-t^{*}\right)}}{n^{4} \pi^{4}}\right)}{1+\frac{1}{n^{2} \pi^{2}}}\right)\right)(37)
\end{aligned}
$$

\section{Numerical examples}

In this section the main features of the solutions found in the previous section (5.0) will be discussed. This is done in order to see the effect of changes of effective thermal coefficient $\theta_{0}$ to the overall distributions, while keeping other operating conditions and parameters fixed, and ascertain the best one for optimal natural ventilation.

A Physical interpretation of dimensionless temperature profiles for three incremental values of $\theta_{0}=(0.01,0.03,0.05)$ is presented in Figure 4, 5, and 6. In which in Figure 4 as $t^{*}$ increase the corresponding $\dot{\theta}^{*}\left(y^{*}, t^{*}\right)$ increases with $\theta_{0}=0.01$. In Figure 5 as $t^{*}$ increase the corresponding $\dot{\theta}^{*}\left(y^{*}, t^{*}\right)$ increases with $\theta_{0}=0.03$. And in Figure 6 as $t^{*}$ increase the corresponding $\dot{\theta}^{*}\left(y^{*}, t^{*}\right)$ also increases with $\theta_{0}=0.05$. The obvious features to be observed is that, all the lines of flow for temperature profiles across the openings are linearly distributed. Therefore, it is found that the best value of $\dot{\theta}^{*}\left(y^{*}, t^{*}\right)$ for optimal natural ventilation is when $\theta_{0}=$ 0.01 and $t^{*}=t_{\text {max }}=1.0$.

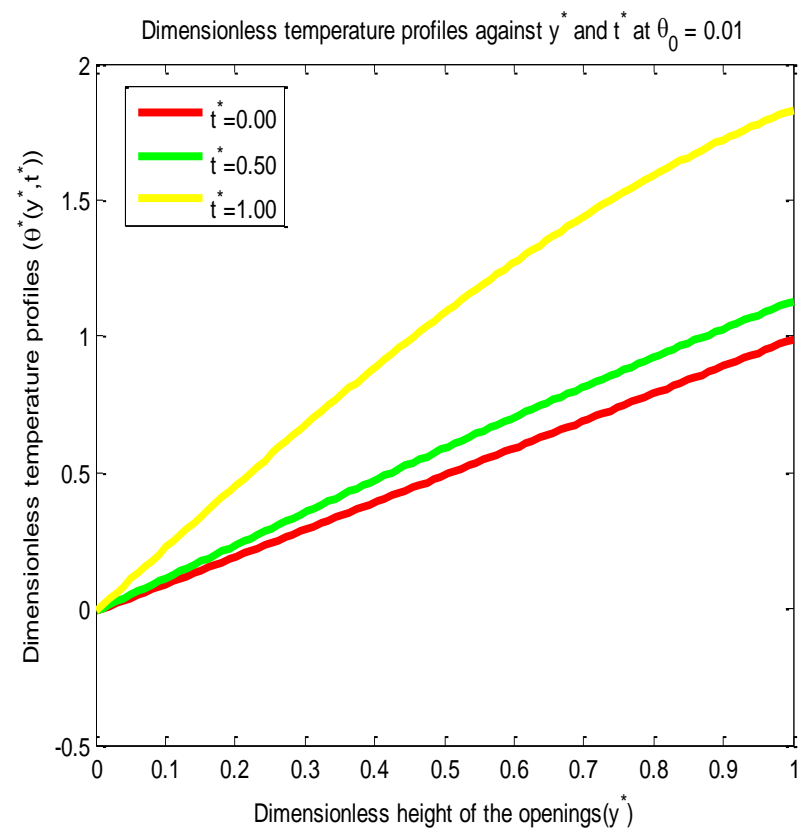

Fig. 4:Dimensionless Temperature Profiles $\dot{\theta}^{*}$ Versus $y^{*}$ and $t^{*} \operatorname{At} \theta_{0}=$ 0.01 . 


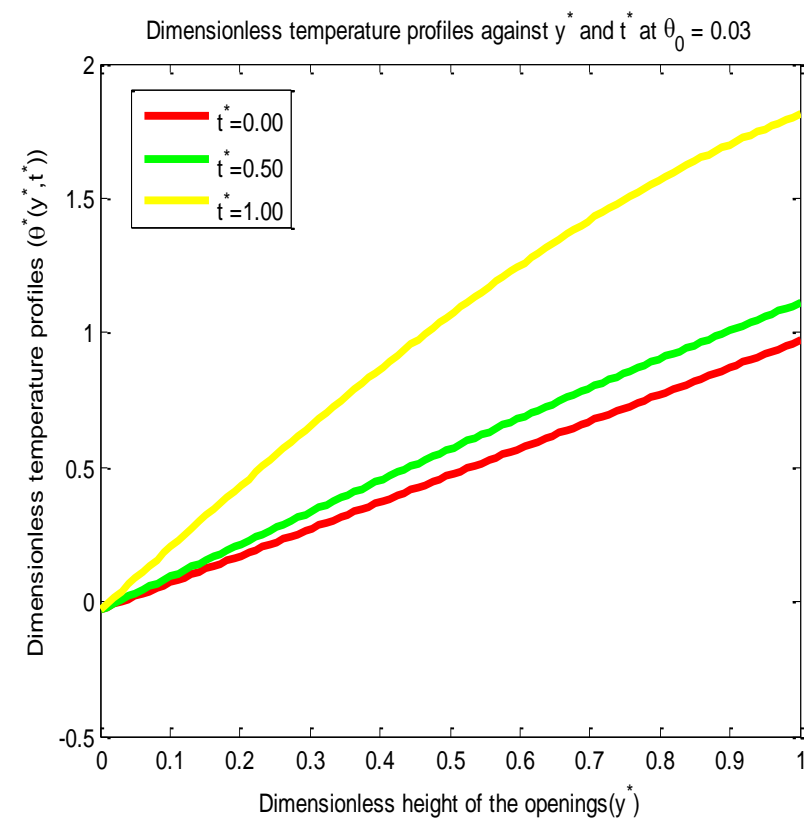

Fig. 5:Dimensionless Temperature Profiles $\dot{\theta}^{*}$ Versus $y^{*}$ and $t^{*}$ at $\theta_{0}=$ 0.03

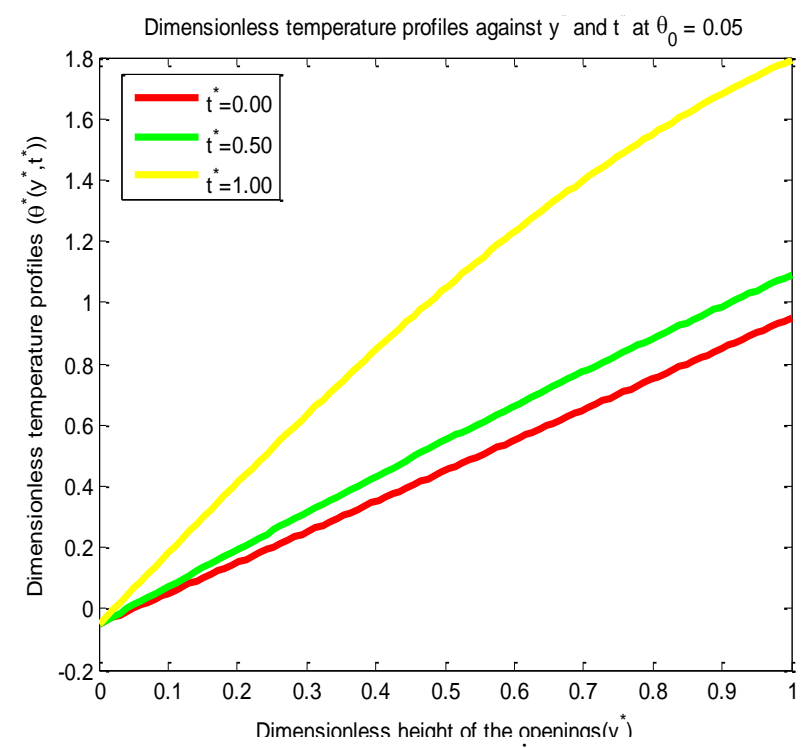

Fig. 6:Dimensionless Temperature Profiles $\dot{\theta}^{*}$ versus $y^{*}$ and $t^{*}$ at $\theta_{0}=$ 0.05

A Physical interpretation of dimensionless velocity profiles for three incremental values of $\theta_{0}=(0.01,0.03,0.05)$ is presented in Figure 7, 8, and 9. In which in Figure 7 as $t^{*}$ increase the corresponding $U^{*}\left(y^{*}, t^{*}\right)$ increases with $\theta_{0}=0.01$. In Figure 8 as $t^{*}$ increase the corresponding $U^{*}\left(y^{*}, t^{*}\right)$ increases with $\theta_{0}=0.03$. And in Figure 9 as $t^{*}$ increase the corresponding $U^{*}\left(y^{*}, t^{*}\right)$ also increases with $\theta_{0}=0.05$. The obvious features to be observed is that, as $t^{*}$ increases the line of flow for velocity profiles across the openings also increases. Therefore, it is found that the best value of $U^{*}\left(y^{*}, t^{*}\right)$ for optimal natural ventilation is when $\theta_{0}=0.01$. and $t^{*}=t_{\max }=1.0$

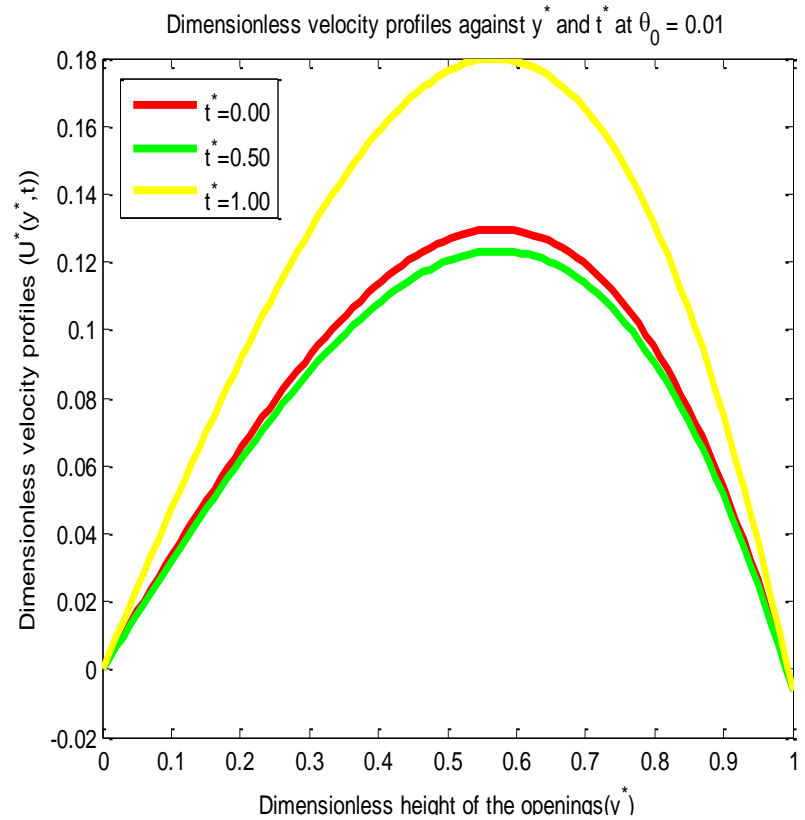

Fig. 7:Transient Dimensionless Velocity Profiles $U^{*}$ Versus $y^{*}$ and $t^{*}$ at $\theta_{0}=0.01$.

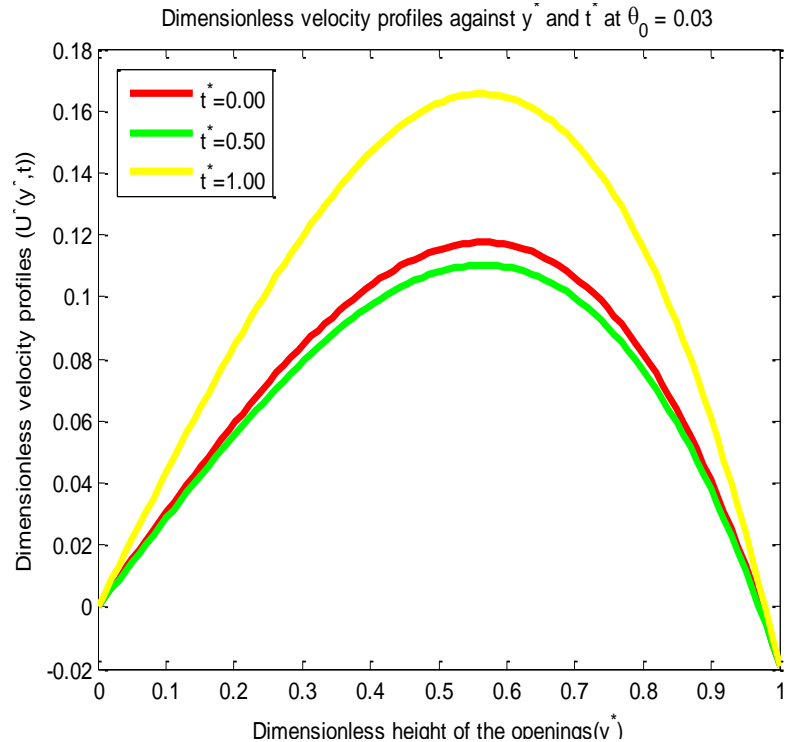

Fig. 8:Transient Dimensionless Velocity Profiles $U^{*}$ versus $y^{*}$ and $t^{*}$ at $\theta_{0}=0.03$.

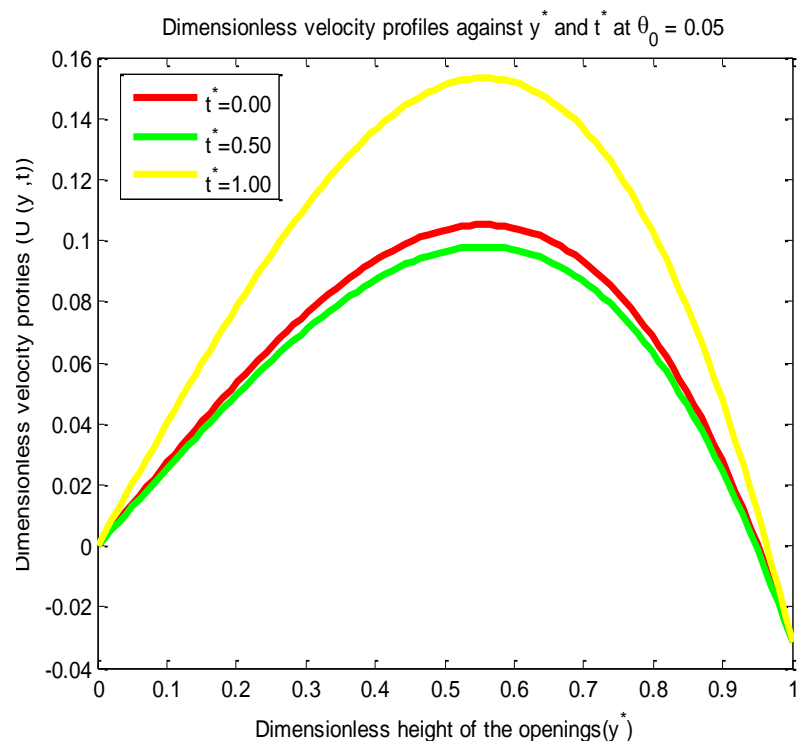

Fig. 9:Transient Dimensionless Velocity Profiles $U^{*}$ Versus $y^{*}$ and $t^{*}$ at $\theta_{0}=0.05$. 
A Physical interpretation of dimensionless volumetric airflow for three incremental values of $\theta_{0}=(0.01,0.03,0.05)$ is presented in Figure 10, 11, and 12. In which in Figure 10 as $t^{*}$ increase the corresponding $Q^{*}\left(y^{*}, t^{*}\right)$ increases with $\theta_{0}=0.01$. In Figure 11 as $t^{*}$ increase the corresponding $Q^{*}\left(y^{*}, t^{*}\right)$ increases with $\theta_{0}=0.03$. And in Figure 12 as $t^{*}$ increase the corresponding $Q^{*}\left(y^{*}, t^{*}\right)$ also increases with $\theta_{0}=0.05$. The obvious features to be observed is that, as $t^{*}$ increases the volumetric airflow also increases. Therefore, it is found that the best value of $Q^{*}\left(y^{*}, t^{*}\right)$ for optimal natural ventilation is when $\theta_{0}=0.01$ and $t^{*}=t_{\max }=1.0$.

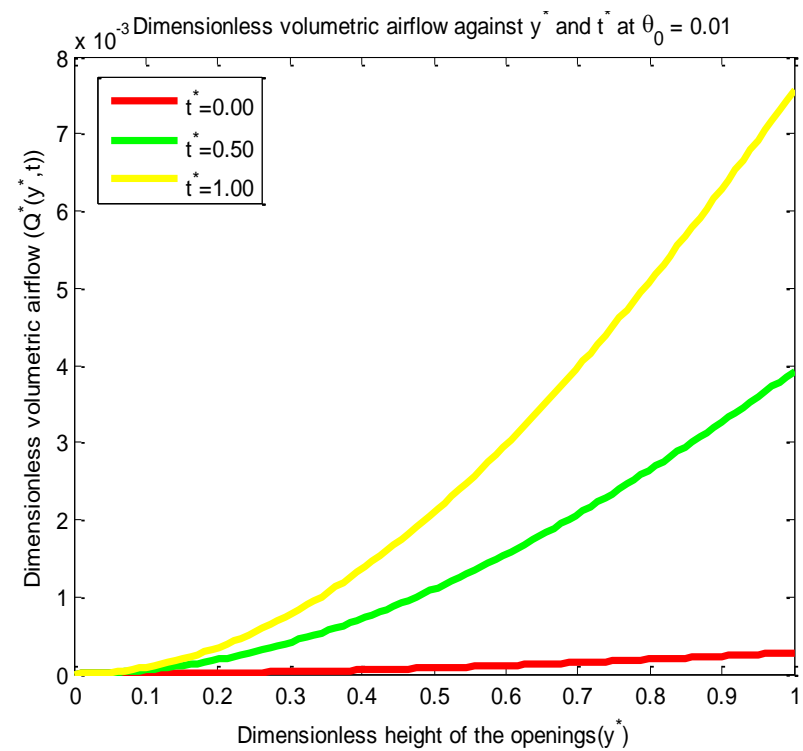

Fig. 10:Transient Dimensionless Volumetric Airflow $Q^{*}$ versus $y^{*}$ and $t^{*}$ at $\theta_{0}=0.01$.

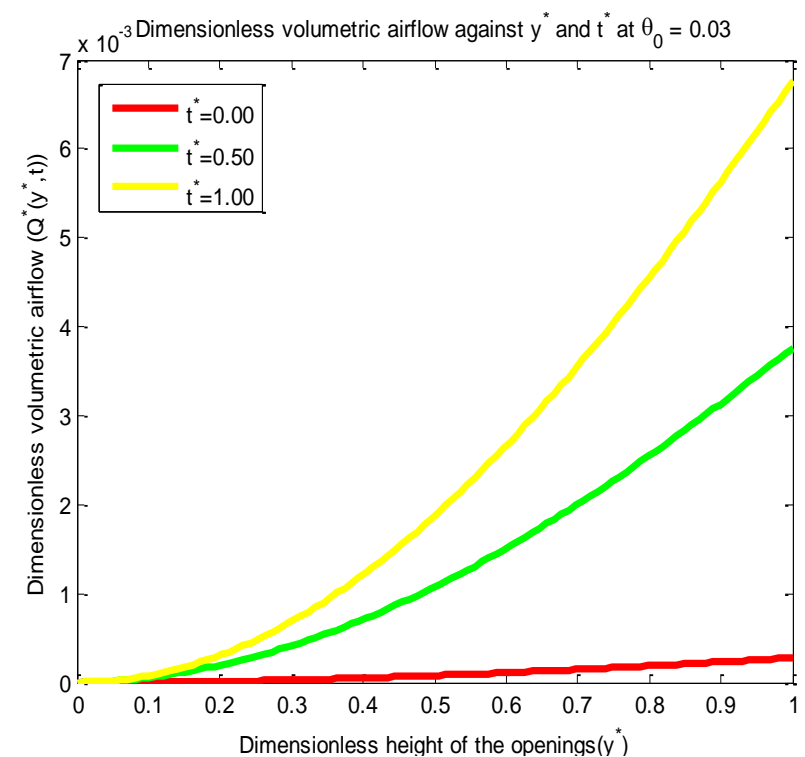

Fig. 11:Transient Dimensionless Volumetric Airflow $Q^{*}$ versus $y^{*}$ and $t^{*}$ At $\theta_{0}=0.03$.

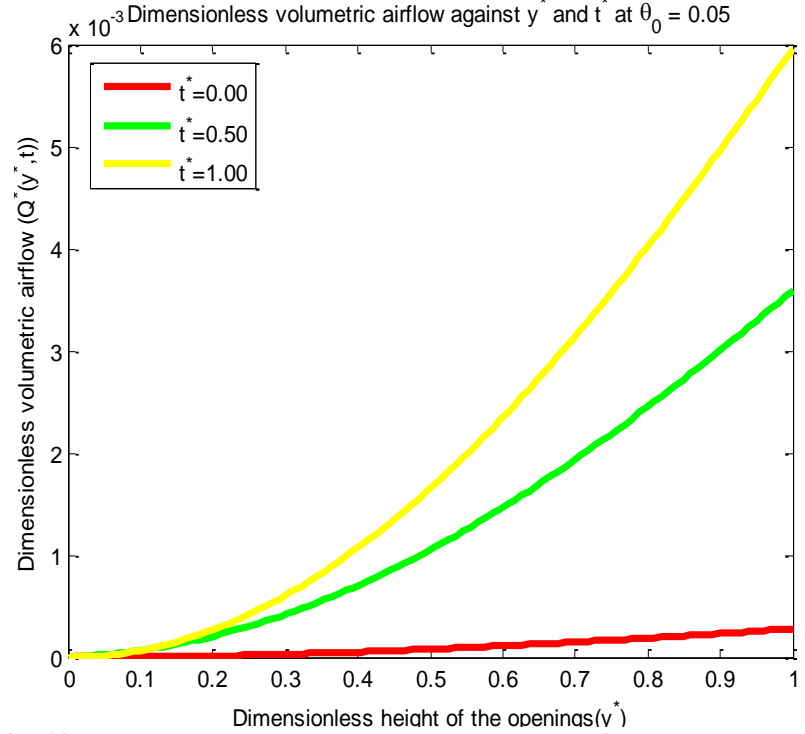

Fig. 12:Transient Dimensionless Volumetric Airflow $Q^{*}$ versus $y^{*}$ and $t^{*}$ at $\theta_{0}=0.05$.

A Physical interpretation of dimensionless mass transfer for three incremental values of $\theta_{0}=(0.10,0.30,0.50)$ is presented in Figure 13, 14, and 15. In which in Figure 13 as $t^{*}$ increase the corresponding $m^{*}\left(y^{*}, t^{*}\right)$ increases with $\theta_{0}=0.01$. In Figure 14 as $t^{*}$ increase the corresponding $m^{*}\left(y^{*}, t^{*}\right)$ increases with $\theta_{0}=0.03$. And in Figure 15 as $t^{*}$ increase the corresponding $m^{*}\left(y^{*}, t^{*}\right)$ also increases with $\theta_{0}=0.05$. The obvious features to be observed is that, as $t^{*}$ increases the mass transfer also increases. Therefore, it is found that the best value of $m^{*}\left(y^{*}, t^{*}\right)$ for optimal natural ventilation is when $\theta_{0}=0.01$ andt $^{*}=t_{\max }=1.0$.

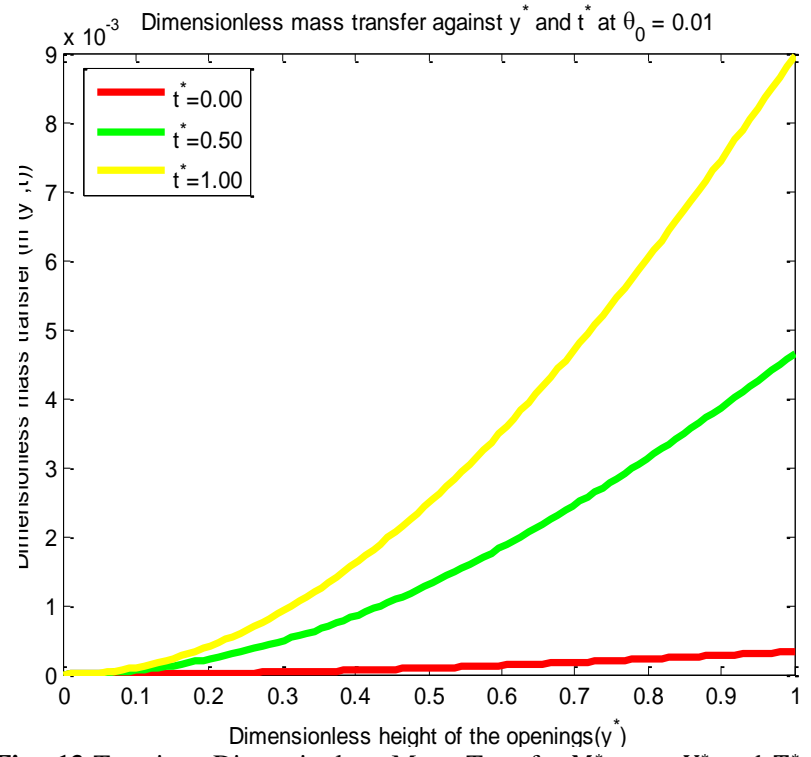

Fig. 13:Transient Dimensionless Mass Transfer $\mathrm{M}^{*}$ versus $\mathrm{Y}^{*}$ and $\mathrm{T}^{*}$ at $\Theta_{0}=0.01$. 


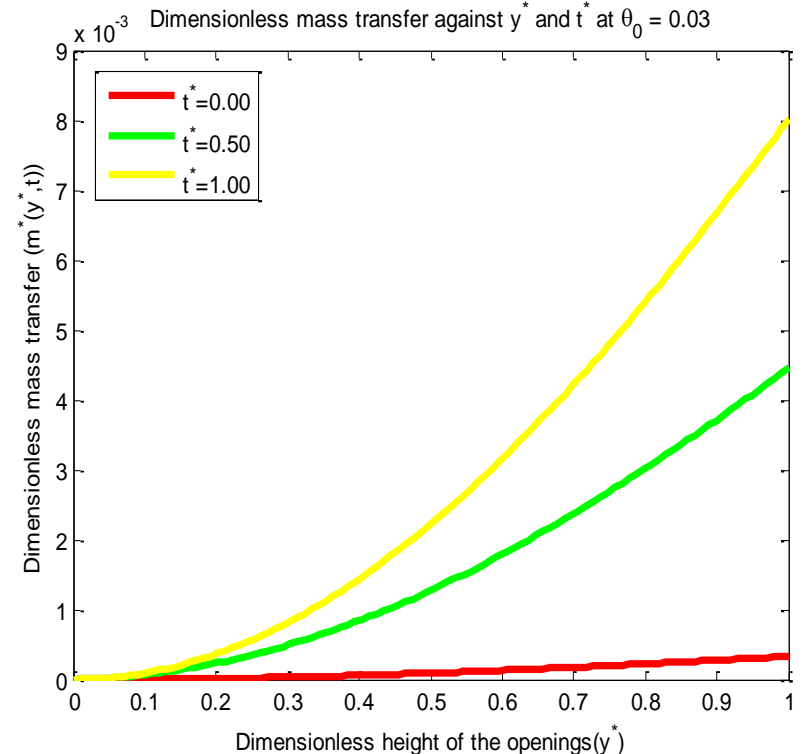

Fig. 14: Transient Dimensionless Mass Transfer $\mathrm{M}^{*}$ Versus $\mathrm{Y}^{*}$ and $\mathrm{T}^{*}$ at $\Theta_{0}=0.03$

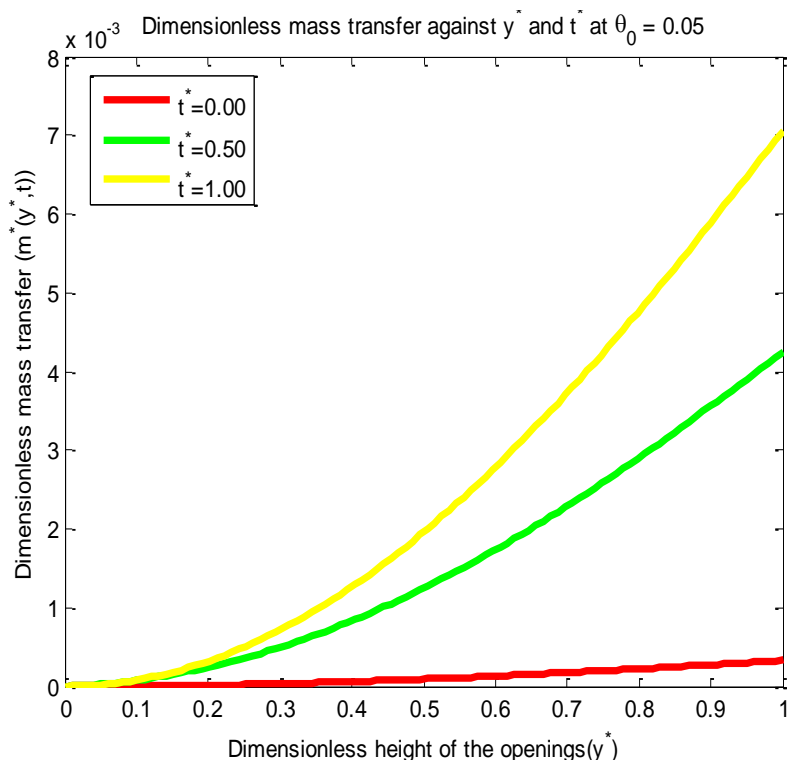

Fig. 15: Transient Dimensionless Mass Transfer $\mathrm{M}^{*}$ Versus $\mathrm{Y}^{*}$ and $\mathrm{T}^{*}$ at $\Theta_{0}=0.05$.

\section{Conclusion}

A Transient investigation of stack- driven airflow process through rectangular cross- ventilated building with two vents in the absence of opposing flow in one of the upper opening was presented. Parameters such as, effective thermal coefficient and Prandtl number were also introduced, which were believed to have significant effects on natural ventilation process in buildings. Analytical techniques were employed to obtain the possible solutions of the model Equations, which predicts velocity- and temperature profiles together with volumetric airflow and mass-transfer. Various parameters on air flow process were used to see the effect of changes of effective thermal coefficient $\theta_{0}$ for different time intervals $\left(t^{*}\right)$ to the overall flow distributions, and ascertain the best one for optimal natural ventilation. Therefore, expected objectives in the paper are achieved.

The paper lead to the following conclusions:

1) A decrease in effective thermal coefficient $\theta_{0}$ results in an increase in temperature profiles $\dot{\theta}^{*}$ across the openings. The temperatures profiles $\dot{\theta}^{*}$ is more sensitive at lower values of effective thermal coefficient $\theta_{0}$. Therefore, the main features to be observed is that the temperature profiles $\dot{\theta}^{*}$ was within comfortable conditions for higher value of time intervalst*
2) A decrease in effective thermal coefficient $\theta_{0}$ results in an increase in velocity profiles $U^{*}$ across the openings. The velocity profiles $U^{*}$ is more sensitive at lower values of effective thermal coefficient $\theta_{0}$. Therefore, the main features to be observed is that the velocity profiles $\mathrm{U}^{*}$ is higher in comparison to higher value of time intervalst*.

3) A decrease in effective thermal coefficient $\theta_{0}$ result in an increase in volumetric airflow $Q^{*}$. The volumetric airflow $Q^{*}$ is more sensitive at lower values of effective thermal coefficient $\theta_{0}$. Therefore, the main features to be observed is that the volumetric airflow $\mathrm{Q}^{*}$ is higher in comparison to higher value of time intervalst*.

4) An increase in effective thermal coefficient $\theta_{0}$, result in an increase in mass transferm* ${ }^{*}$ The mass transfer $\mathrm{m}^{*}$ is more sensitive at lower values of effective thermal coefficient $\theta_{0}$. Therefore, the main features to be observed in this research is that the mass transfer $\mathrm{m}^{*}$ is higher in comparison to higher value of time intervalst*.

5) The greater vertical distance between the openings, and the greater temperature difference between the inside and the outside, the stronger is the effect of the buoyancy.

The model is only valid for cross- ventilated building with two openings at the same height.

\section{Acknowledgement}

The authors are grateful, to authorities of Tertiary Education Trust Fund (TETFUND), Nigeria and that of Kano University of Science and Technology, Wudil (KUST) for granting the leave and funds to conduct the research.

\section{References}

[1] Allocca, C., Chen, Q., and Glicksman, L.R. (2003). Design analysis of single-sided natural ventilation Energy and Buildings. 35(8), 785- 795.

[2] M.Santamouris, A. Argiriou, D. Asimakopoulos, N. Klitsikas, A. Dounis (1995). Heat and Mass- transfer through large openings by natural convection. Energy and Buildings 23.

[3] Roberto Fuliotto et al. (2010)," Experimental and Numerical analysis of heat transfer and airflow on an interactive building façade". Energy and Buildings. $42(1)$, 23 28.https://doi.org/10.1016/j.enbuild.2009.07.006.

[4] Yuguo Li, Angelo Delsante, Je Symons (2000). Prediction of natural ventilation in buildings with large openings. Builing and Environment 35, 191- 206. https://doi.org/10.1016/S0360-1323(99)000116.

[5] C.L. Chow (2010). Airflow rate across vertical opening induced by room heat sources. International Journal on Architectural Science Volume 8, Number 1.11- 16

[6] Liang Chung James Lo, (2012). Predicting wind driven cross ventilation in buildings with small openings. Doctoral thesis. University of Texas U. S. A.

[7] Andrew Acred, Gary R. Hunt (2014). A simplified mathematical approach for modelling stack ventilation in multi-compartment buildings. Builing and Environment 71, 121130.https://doi.org/10.1016/j.buildenv.2013.09.004.

[8] A. L. Muhammad and A. B. Baffa (2015). Airflow process across vertical vents induced by stack- driven effect with an opposing flow in one of the upper openings. International Journal of Computer Application (IJCA). Volume 123(1). 18.https://doi.org/10.5120/ijca2015900728.

[9] A. L. Muhammad and A. B. Baffa and M. Z. Ringim (2016). Investigation of stack- driven airflow through rectangular cross- ventilated building with two openings using analytic technique. International Journal of Computer Application (IJCA). Volume 141(6). 511.https://doi.org/10.5120/ijca2016909631. 